\title{
Social and educational setting to prepare pre- school children for study through physical education
}

\author{
Maria Leont'eva, Tatiana Levchenkova ${ }^{*}$, and Tamara Mikhailova \\ ${ }^{1}$ Russian State University of Physical Education, Sport, Youth and Tourism, 105122, Moscow, Russia
}

\begin{abstract}
The challenge of preparing children for study in school has acquired particular significance in the present moment. The pre-school training programmes need to be comprehensive, involving tools and methods aimed at the development of motor, intellectual, psychological and emotional abilities. A physical education programme based primarily on play method and teaching kids to play badminton, is an effective means to get children ready for school studies. An 8-month trial of this programme, implemented as part of physical education for pre-school age children attending kindergarten or a fitness club, demonstrated an improvement in the kids' psychological and emotional qualities (assessed via Lüscher colour test), as well as physical fitness (assessed via physical fitness tests), and confirmed the kids' readiness for school studies (through Kern-Irasek test).
\end{abstract}

\section{Introduction}

The social and economic changes happening both in Russia and worldwide demand a reassessment of many traditional approaches to education and training of younger generations.

A quality education received in general and secondary school becomes particularly significant in helping the young generation adapt to modern life. Specifically important is the issue of continuity between pre-school and regular school training. This is due to the recent appearance of a large number of private education centres, clubs, and early learning studios that offer uniquely designed training programmes. These organisations provide an alternative to traditional public kindergartens in terms of caring for pre-school children. They organise classes in smaller groups, are better equipped, and often have more diverse activities. This provides a more individualised approach to the child's upbringing and teaching.

As the education system becomes more considerate and democratic, while private preschool and public primary school study programmes become more varied, the matter of continuity between these programmes grows as relevant as ever. It manifests sharply in practice, when a certain category of children appears unprepared for systematic, focused

* Corresponding author: tatlev811@mail.ru 
study at school and requires a long and difficult adaptation to the new learning environment. [1]

As kids begin to attend classes, they significantly reduce their motion activities $[2,3]$. It affects their physical and emotional condition. Therefore, comprehensive preparation of children for school is required that involves intellectual, psychological and physical education. The readiness for school is understood as a combination of morphophysiological and psycho-physiological qualities that allows an older pre-school age child to successfully transition to organised school education [4]. Bezrukikh and Efimova [5] provide the following definition: "The readiness for school is such a level of a child's morphological, functional and psychological development when the demands of systematic study are not excessive and do not impair the health of the child."

A rationally organised process of physical education can solve a whole set of problems concerning disadaptation and effective preparation of pre-school children to school studies. The main goal of physical education remains the nurturing of physical abilities and the development of the locomotor system able to withstand the static physical pressures experienced at school. If we primarily use a play method to organise P.E. classes, we can help the child develop their intellectual and emotional-volitional spheres, initiative, communicative skills, and discipline. Peter Lesgaft [6] emphasised that physical education should not be limited only to improving a person's health and fitness or sports skills, but needs to organically involve mental, ethical, labour and aesthetical development: only this combination can realise the general purpose of education, which according to Lesgaft is "harmonised comprehensive development of the human organism function ".

The relevance of our research is concerned with validating the modern tools and methods of physical education as well as conditions for their implementation. They are necessary to ensure the kids' readiness for school instruction.

\section{Materials and Methods}

In our research, we employed both theoretical and practical study methods. A questionnaire was used to gauge the opinion of parents and teachers on whether they considered physical education tools and methods necessary for school preparation. The questionnaire had 15 items, and 180 parents and 95 teachers were surveyed in total.

In pre-school institutions, we employed pedagogical observation, analysing the amount and content of the kids' physical activities. We studied the content of children's classes in local and fitness clubs.

The physical fitness level was assessed via tests: standing long jump, shuttle run $(3 \times 10 \mathrm{~m})$, standing forward bends, and squats within 30 seconds.

The children's emotional state was evaluated via the 8-colour Lüscher test. [7]

The readiness for study was determined through the Kern-Irasek assessment test. [5]

The Kern-Irasek test included three tasks for the children to complete: drawing a human figure, copying an unfamiliar set of strokes (letters in a phrase 'He ate soup'), and copying a set of 10 drawn dots maintaining the vertical and horizontal distances between them. Each test was graded by 5 points, with 1 being the worst and 5 being the best grade. The child's grades for each task were totalled. Children determined to be ready for school normally received from 3 to 9 points.

\section{Results and Discussion}

During the survey of the parents, all of the participants were positive that pre-school age children require preparation before they can successfully enter school. Among the 
surveyed, 54\% of parents believe that preparation should be focused on the children's intellectual development, $29 \%$ believe the focus should be on fitness and health, while $17 \%$ believe that it is necessary to nurture the child's emotional-volitional sphere.

According to the teachers' survey, preparation of children for school is believed to require a comprehensive approach. In the opinion of teachers, approximately equal time should be devoted to the kids' intellectual, physical and emotional-volitional development (respectively $36 \%, 30 \%$ and $34 \%$ ).

In our pedagogical observation, we analysed the amount and content of pre-school children's weekly physical activities. We primarily focused on the time assigned to specially organised classes during a day in kindergarten (Table 1).

Table 1. Time per week (minutes) of physical activity for older pre-school children in kindergarten.

\begin{tabular}{|l|c|c|}
\hline \multicolumn{1}{|c|}{ Formats of Work } & $\mathbf{5 - 6}$ y.o. & 6-7 y.o. \\
\hline $\begin{array}{l}\text { Dynamic games and outdoor physical exercise (morning, } \\
\text { afternoon) }\end{array}$ & 200 & 200 \\
\hline Games, round dances, game exercise during the day & 125 & 150 \\
\hline Music and rhythm classes & 90 & 105 \\
\hline Game therapy & 30 & 30 \\
\hline Supervised game room visits & 40 & 40 \\
\hline Morning hygienic gymnastics & 10 & 10 \\
\hline Post daytime sleep gymnastics & 5 & 5 \\
\hline TOTAL & 500 & 540 \\
\hline
\end{tabular}

The results show that time specifically devoted to physical activity for 6 to 7 year old children amounts to about 110 minutes per day (i.e. 1 hour 50 minutes). Each format of work uses physical exercise, dynamic games, and special tasks aimed at developing the child's motor skills. Not all work formats are used daily. Dynamic games and outdoor physical exercise (morning and afternoon), as well as games, round dances, and game exercise during the day, are compulsory and take place each day. Other activity types are scheduled 1 or 2 times a week.

For primary school students, during the study period the everyday physical activity plummets. If kids do not attend any extracurricular sports or health and fitness classes, their physical activity is limited to three physical education lessons only, which amounts to 135 minutes per week or roughly 20 minutes per day. This reduction in movement proves that a focused physical preparation for school studies is appropriate.

Taking the above into account, we developed a dedicated physical education programme for older pre-school age children that was used in kindergartens and fitness clubs for 8 months during September 2018 - April 2019.

In designing the physical education process aimed at school readiness, we strived to develop sets of specialized exercise that, when combined with other educational efforts, would promote not only an improvement in physical fitness, but also the focused development of pre-school children's intellectual, physical and emotional abilities.

The physical education programme was built around using primarily the play method of teaching physical activity. This approach was chosen because for pre-school kids, the main type of activity is play [8]. Play can help the child develop new perception, emotional- 
volitional, psychological, physiological, and motor abilities and skills. Play for kids is exciting, so using it in physical education provides a positive effect on the child's personal development and preparation for school studies. [9-11]

The core part included games and exercise with balls of different sizes, as well as exercise for back and abdominal muscles, posture, flat foot, flexibility, and coordination. Three 40-minute classes were scheduled every week.

The feature of our pre-school physical education programme was the use of badminton games. They were included for being highly exciting and accessible to children of any fitness level. Compared to other sports, the advantage of badminton is the lack of constant stresses, as well as the large role and amount of complex hand and arm movement coordination. During early classes, badminton does not involve teamwork, allowing each child to express themselves and develop individually. Playing helps expand motor skills, teaches to precisely assess movement in terms of space, time and force, improves health as well as physical and mental capacities, and develops the child's psychological and emotional sphere.

One of the first things taught at school is learning to write. This necessitates significant development of the hand. It has been established that badminton techniques and graphical writing skills have the following things in common:

- Micro-movements of hand in terms of shape and direction

- Conscious micro-movement control

- The speed of performed actions

- The complexity of movements

- Dividing attention and being conscious of multiple tasks simultaneously

As content for our badminton pre-school physical education classes, we've included the following:

- Badminton lead-up skills exercise (shuttlecock throw, tossing it from one hand to the other, juggling, wrist joint movement and flexibility exercise)

- Special exercise including vertical and horizontal 'eights', spirals, wavy lines, drawing letter parts or whole letters by outlines, mock racket hits, hung up shuttlecock hits

- Complex exercise involving court movement, running hits, sets of hits, and game combinations

- Play exercise (dynamic games, relaxed-rules badminton)

The Lüscher's colour selection test results (Table 2) have shown that at the start of the programme, children attending fitness club classes have somewhat better psychological and emotional state compared to kindergarten children. At the end of the programme, both groups of children showed improvement in this area.

Table 2. Psychological and emotional state of pre-school age children via Lüscher test (\% of participants).

\begin{tabular}{|l|c|c|c|c|}
\hline \multirow{2}{*}{ Metrics } & \multicolumn{2}{|c|}{$\begin{array}{c}\text { Children attending kindergarten } \\
(\mathrm{n}=56)\end{array}$} & \multicolumn{2}{c|}{$\begin{array}{c}\text { Children attending a fitness club } \\
(\mathrm{n}=48)\end{array}$} \\
\cline { 2 - 5 } & $\begin{array}{c}\text { start of } \\
\text { programme }\end{array}$ & $\begin{array}{c}\text { end of } \\
\text { programme }\end{array}$ & $\begin{array}{c}\text { start of } \\
\text { programme }\end{array}$ & $\begin{array}{c}\text { end of } \\
\text { programme }\end{array}$ \\
\hline Healthy attitude & 42,3 & 53,2 & 45,4 & 52,9 \\
\hline Discomfort & 26,9 & 21,6 & 17,2 & 16,1 \\
\hline $\begin{array}{l}\text { Psychological } \\
\text { stress }\end{array}$ & 23,1 & 17,9 & 18,1 & 16,3 \\
\hline Disadaptation & 7,7 & 7,2 & 7,1 & 6,5 \\
\hline
\end{tabular}


During the study, we analysed the physical fitness of pre-school age children, with results shown in Table 3 .

Table 3. Physical fitness of pre-school age children.

\begin{tabular}{|l|c|c|c|c|}
\hline \multirow{2}{*}{ Tests } & \multicolumn{2}{|c|}{$\begin{array}{c}\text { Children attending } \\
\text { kindergarten }(\mathrm{n}=56)\end{array}$} & \multicolumn{2}{c|}{$\begin{array}{c}\text { Children attending a fitness } \\
\text { club (n=48) }\end{array}$} \\
\cline { 2 - 5 } & $\begin{array}{c}\text { start of } \\
\text { programme }\end{array}$ & $\begin{array}{c}\text { end of } \\
\text { programme }\end{array}$ & $\begin{array}{c}\text { start of } \\
\text { programme }\end{array}$ & $\begin{array}{c}\text { end of } \\
\text { programme }\end{array}$ \\
\hline $\begin{array}{l}\text { Standing long jump } \\
(\mathrm{cm})\end{array}$ & $67,1 \pm 3,1$ & $79,3 \pm 4,1$ & $65,9 \pm 2,9$ & $81,2 \pm 3,1$ \\
\hline Shuttle run (sec) & $14,1 \pm 0,3$ & $13,1 \pm 0,4$ & $13,8 \pm 0,5$ & $12,9 \pm 0,6$ \\
\hline Forward bend (cm) & $6,4 \pm 0,6$ & $7,5 \pm 0,9$ & $6,2 \pm 1,0$ & $7,1 \pm 0,9$ \\
\hline Squats (\# times) & $20,8 \pm 1,03$ & $22,9 \pm 1,3$ & $21,1 \pm 1,07$ & $22,6 \pm 1,9$ \\
\hline
\end{tabular}

Comparing the results between children who take part in the programme based in kindergarten versus a fitness club, we see that at the beginning, kindergarten children show better results in flexibility and long jumps. Those who attend a fitness club had better results in squats and shuttle run. At the conclusion of our play method and badminton based programme, the results of both groups in all areas significantly improved. In the 'standing long jump' test, the jump length for kindergarten children increased by $15.4 \%$ and for fitness club kids by $18.9 \%$. In the 'shuttle run' test, the increase amounted to $8.1 \%$ and $6.4 \%$ respectively. Flexibility among kindergarten kids improved by $14.7 \%$ and among fitness club kids by $13.7 \%$. In the 'squats' test, the improvement was respectively $9.2 \%$ and $6.7 \%$.

The readiness for study was evaluated using the Kern-Irasek assessment test and Venger's graphical dictation [5]. The Kern-Irasek test can assess the child's fine motor skills as well as determine visual attentiveness and hand coordination. By analysing the drawing, we can evaluate the child's memory and spatial intelligence, and make conclusions of the future student's development level. Observing the child's behaviour during the test helps determine their ability to closely follow an example, as well as their diligence and concentration. These are material factors in determining the child's readiness for school study.

According to the Kern-Irasek test, by the end of the programme 52.2\% of kids attending a fitness club and $54.3 \%$ of kindergarten children demonstrate a moderate development level ( 3 to 9 points), making them provisionally ready for school instruction. In this group, the main errors were observed in copying a text. However, daily teacher-led classes in writing, drawing, moulding and other activities helped most children perform other tests (human figure drawing, copying dots) sufficiently well. Furthermore, movement skills obtained during the health and fitness class were successfully transferred to writing skills acquisition.

The implementation of the pre-school children physical education programme based on the play method and teaching of badminton proved effective in preparing children for school study. The most significant changes were observed in testing the children's movement skills. Improvements also occurred in psychological and emotional development, ensuring the kids' readiness for school instruction.

\section{Conclusion}

Getting the pre-school age children ready for school currently presents a significant social and educational challenge. This task can be solved only by ensuring maximum possible 
continuity from pre-school education and training programmes used in various kinds of institutions.

Programmes need to be comprehensive, combining tools and methods aimed at developing the children's physical, intellectual, as well as psychological and emotional abilities.

The pre-school children physical education programme based on play method and involving badminton, presented here, has demonstrated its effectiveness. This programme can be used both in public and private pre-school children's education institutions that offer physical education and sports.

\section{References}

1. A.Ya.Varlamova, School Adjustment (VolGU, Volgograd, 2015)

2. T.V. Levchenkova, Theory \& Practice of Phys. Cult., 5, 57-58 (2004)

3. E.Ya. Stepanenkova, Theory and Methods of Physical Education and Child Development: Textbook for Higher Education Students (Publishing Centre 'Akademiya', Moscow, 2006)

4. E.E. Kravtsova, Psychological Issues in Children's Readiness for School (Pedagogika, Moscow, 2015)

5. M.M. Bezrukikh, S.P. Efimova, Do You Know Your Pupil? (Prosveschenie, Moscow, 1991)

6. P.F. Lesgaft, Selected Works (compiled by I.N. Resheten', FiS, Moscow, 1987)

7. I.A. Koretskaya, Psychodiagnostics: Teaching Materials (Eurasian Open Institute, Moscow, 2011)

8. A.S. Kuznetsov, Z.M. Kuznetsova, Russian Journal of Physical Education and Sport, 14(4), 5-7 (2019). DOI: 10.14526/2070-4798-2019-14-4-5-7

9. T.V. Levchenkova, Sports Psych., 2, 90-93 (2013)

10. M.S. Leont'eva, Theory \& Practice of Phys. Cult., 12, 29-31 (2018)

11. A.P. Scherbak, Thematic Physical Education Classes and Festivals in a Pre-School Institution: The Influence of Physical Education on Behavioural Self-Regulation of a Pre-School Child: Teaching Guidance for Pre-School Teachers (Vlados, Moscow, 2001) 